\title{
Incorporação das TDIC e o desenvolvimento do trabalho docente
}

\author{
Rosemar Rosa \\ Instituto Federal do Triângulo Mineiro - Campus Uberaba - IFTM, Brasil \\ Sálua Cecílio \\ Universidade de Uberaba - UNIUBE, Brasil
}

\begin{abstract}
RESUMO
A incorporação das Tecnologias Digitais da Informação e Comunicação (TDIC) no contexto educacional afeta o trabalho docente, exigindo dos professores formação profissional, novas ações pedagógicas e conhecimento sobre os desafios e os potenciais educativos das TDIC. Nesse sentido, este trabalho, de natureza bibliográfica, tem como objetivo apontar desafios, potenciais educativos ocasionados pelo uso das TDIC no trabalho docente. Foi desenvolvido a partir da questão: quais desafios e potenciais educativos que a incorporação das TDIC apresenta ao desenvolvimento do trabalho docente? Os resultados apontam que, para a superação dos desafios e o alcance dos potenciais educativos das TDIC, a mudança no fazer pedagógico se faz necessária. Isso implica ações comunicativas, pelas e para as quais, os docentes necessitam se preparar continuamente. Nas considerações finais é destacado que os professores têm desafios a enfrentar, novos conhecimentos para adquirir, e por isso se faz necessária a formação para atuar na cultura virtual.
\end{abstract}

PALAVRAS-CHAVE: Trabalho docente. Tecnologias Digitais da Informação e Comunicação. Potenciais educativos.

\section{INCORPORATION OF DICT AND THE DEVELOPMENT OF TEACHING WORK}

\begin{abstract}
The incorporation of Digital Information and Communication Technologies (DICT) in the educational context it affects the teaching work, requiring from teachers professional training, new pedagogical actions and knowledge about the challenges and educational potentials of DICT. In this sense, this work, of a bibliographic nature, aims to point out challenges, educational potentials caused by the use of DICT in teaching work. The results show that, in order to overcome the challenges and reach the educational potential of TDIC, the change in pedagogical practice is necessary. This implies communicative actions, by and for which, teachers need to prepare continuously. In the final remarks, it is highlighted that teachers have challenges to face, new knowledge to acquire, and that is why training to work in the virtual culture is necessary.
\end{abstract}

KEYWORDS: Teaching work. Digital Technologies of Information and Communication. Educational potentials. 


\section{INCORPORACIÓN DE TDIC Y DESARROLLO DEL TRABAJO DOCENTE}

\section{RESUMEN}

La incorporación de las Tecnologías Digitales de Información y Comunicación (TDIC) en el contexto educativo afecta el trabajo docente, requiriendo de los docentes capacitación profesional, nuevas acciones pedagógicas y conocimiento sobre los desafíos y el potencial educativo de TDIC. En este sentido, este trabajo, de naturaleza bibliográfica, apunta a señalar los desafíos, los potenciales educativos causados por el uso de TDIC en el trabajo docente. Se desarrolló a partir de la pregunta: ¿qué desafíos y potenciales educativos presenta la incorporación de TDIC en el desarrollo del trabajo docente? Los resultados muestran que, para superar los desafíos y alcanzar los potenciales educativos de TDIC, es necesario un cambio en la práctica pedagógica. Esto implica acciones comunicativas, por las cuales, los maestros necesitan prepararse continuamente. En las observaciones finales, se destaca que los maestros tienen desafíos que enfrentar, nuevos conocimientos que adquirir, y es por eso que se necesita capacitación para trabajar en la cultura virtual.

PALABRAS CLAVE: Trabajo docente. Tecnologías digitales de información y comunicación. Potenciales educativos

\section{INTRODUÇÃO}

Vários pesquisadores da área educação realizam pesquisas para descobrir quais desafios e potenciais educativos as Tecnologias Digitais da Informação e Comunicação - TDIC - trazem ao desenvolvimento do trabalho docente. Tendo em vista que, no ambiente acadêmico, uma das questões que mais se discute é sobre habilidades, aptidões para entender, interagir, utilizar metodologias didáticas de modo a incorporar as TDIC nas práticas educativas para beneficiar o aprendizado; dado que estamos inseridos em uma sociedade em que a cultura virtual tem se expandido cada vez mais. Alguns veem, nas TDIC, a perspectiva de favorecer o desenvolvimento do trabalho docente, embora importe considerar que há desafios ainda associados à sua incorporação no processo educativo, que exige formação, novas ações pedagógicas e o conhecimento dos potenciais educativos das referidas tecnologias no processo ensino-aprendizagem.

A revolução tecnológica se intensificou com o surgimento de novas tecnologias que invadiram o ambiente familiar, educacional, profissional e passaram a mediar a relação entre as pessoas e a criar maneiras de acesso à informação. Uma nova cultura se instalou e a qual podemos chamar de virtual, em que há uma disseminação intensa e rápida da informação via TDIC que, incorporadas à Internet e às redes sociais, se encontram presentes em diversos aparelhos utilizados pelas pessoas, a exemplo os tablets, os celulares, os notebooks, promovendo modificações no fazer, nos tempos e nos espaços de vida e de trabalho. 
Segundo Lévy (1996), a cultura virtual ou “cibercultura” é caracterizada pela cultura do acesso e pela convergência das mídias, processo pelo qual, por meio de um único aparelho, temos acesso a diferentes mídias, a exemplo do celular, operando como filmadora, TV, máquina fotográfica, rádio etc., além de viabilizar a interatividade entre as pessoas. Na cultura virtual, instalam-se novas relações entre sujeitos/tempo/espaço. Estas definem reestruturações e processos de organização social e de trabalho, por meio das TDIC que instauram uma revolução social, novos modos de inserção na realidade e uma nova visão de mundo.

As transformações no desenvolvimento da sociedade contemporânea foram desencadeadas por evoluções tecnológicas. Daí se originaram, se consolidaram e se expandiram múltiplas aplicações voltadas para o setor econômico, social e educacional, embora muitos usos se deem de forma discutível e com alcances ainda restritos para o processo ensinoaprendizagem. Nesse sentido, este trabalho, de abordagem qualitativa, procura, a partir de uma pesquisa bibliográfica, responder à questão: quais os desafios e potenciais educativos que a incorporação das TDIC apresenta ao desenvolvimento do trabalho docente? O objetivo é apontar desafios e potenciais educativos ocasionados pela incorporação das TDIC no desenvolvimento do trabalho docente.

O texto compreende três seções: na primeira, expomos a incorporação das TDIC e os desafios no desenvolvimento do trabalho docente; na segunda, abordamos as TDIC e os potenciais educativos; e, na terceira, ressaltamos documentos oficiais que fazem referências em relação à incorporação e ao uso das TDIC no contexto educacional. Nas considerações finais, destacamos que os professores têm desafios a enfrentar e novos conhecimentos para adquirir, e por isso se faz necessária à formação para o uso das diversas tecnologias presentes na cultura virtual

\section{METODOLOGIA}

O presente trabalho resulta de uma pesquisa bibliográfica, com abordagem qualitativa. De acordo com Cervo, Bervian e Silva (2007, p.60), a pesquisa bibliográfica "procura explicar um problema a partir de referências teóricas publicadas em artigos, livros, dissertações e teses", de forma a permitir o agrupamento de material e análise das contribuições culturais ou científicas sobre determinado assunto, tema ou problema. Para fazer parte do referencial teórico foram selecionadas obras publicadas no período de 2007 a 2017, que abordaram a temática. A pesquisa seguiu as seguintes etapas: primeira - seleção das obras a serem utilizadas (foram selecionados: 11 artigos, 01dissertação, 7 livros e 3 documentos); segunda - fichamentos das obras selecionadas; e terceira - apresentação e discussão dos resultados. 


\section{RESULTADOS}

Novos desafios são sentidos e vivenciados na educação em tempos de cibercultura e, principalmente, no que tange à inserção da cultura virtual, por meio da presença e adoção da internet e outros recursos digitais, no ambiente acadêmico. Partimos do entendimento de que a cultura virtual é o resultado de um conjunto de ações que utilizam a mediação das TDIC como marca social do nosso tempo. Trata-se de uma revolução digital em que "a informação representa o principal ingrediente de nossa organização social, e os fluxos de mensagens e imagens entre as redes constituem o encadeamento básico de nossa estrutura social" (CASTELLS, 2009, p. 55). Desse processo, resultam situações que desafiam a ação dos professores em relação ao processo ensino-aprendizagem.

O processo de integração das TDIC no desenvolvimento do trabalho docente precisaria corresponder à existência de modelos pedagógicos e de currículos que dessem significado educativo ao uso das tecnologias. Posto que, para desenvolver suas práticas pedagógicas de modo a incorporar as TDIC, importa que o docente esteja preparado para interagir com uma geração mais atualizada e mais informada, com novos modos de lidar com a realidade e nela se situar. Afinal, as tecnologias, lideradas pela Internet, permitem o acesso instantâneo à informação e a descoberta de recursos e metodologias passíveis de favorecer a aquisição do conhecimento. $\mathrm{O}$ ensino e a aprendizagem não estão mais restritos ao docente e/ou ao discente. No contexto da cultura virtual, as tecnologias lançam um desafio aos docentes, como o de romper com práticas mecanicistas, para que os novos métodos possibilitem o aprender e o construir conhecimentos.

Isso posto e admitido, seguem os resultados obtidos na pesquisa bibliográfica. Foram definidas três subseções: TDIC - Desafios no desenvolvimento do trabalho docente; TDIC Potenciais educativos e TDIC nos documentos oficiais; as quais são discutidas a seguir.

\subsection{TDIC - Desafios no desenvolvimento do trabalho docente}

Pesquisadores têm apresentado em seus estudos desafios a serem observados na incorporação das TDIC ao trabalho docente, tendo em vista que, segundo eles, a utilização das TDIC demanda mudanças no contexto educacional e competências diferentes no processo de ensino-aprendizagem. Alonso et al (2014), em seus estudos, destacam que a incorporação das TDIC impõe desafios como: desafio da disponibilidade; desafio da construção coletiva e da revisão de papéis e desafio da formação de professores. 
O desafio da disponibilidade das TDIC no ambiente acadêmico não tem sido totalmente vencido, uma vez que há contextos escolares em que as tecnologias estão disponibilizadas apenas em laboratórios de informática sem uso ou pouco utilizadas. Assim, as TDIC podem estar fisicamente presentes no ambiente acadêmico, mas ausentes da "vida acadêmica", do seu cotidiano. Tal ocorrência se deva talvez ao fato de o docente não ter conhecimento dos potenciais educativos das TDIC no processo ensino-aprendizagem, e, por isso, apresenta dificuldade em usar as referidas tecnologias na prática cotidiana e, sobretudo, em se apropriar delas para uso pedagógico.

O desafio da construção coletiva e da revisão de papéis, pode ser apontado como uma construção coletiva de sentidos, via utilização das TDIC no ambiente acadêmico. Essa construção implica uma revisão de papéis. Já que, no contexto da cultura virtual, o docente não é mais o detentor do conhecimento (transmissor ou o repassador). A a ele cabe a tarefa de reconstruir sua identidade ou de construir uma nova identidade que favoreça a consciência e a prática de novos papéis, a exemplo de articulador, de facilitador no processo de aprendizagem (ALONSO et al., 2014). Mesmo imersos na cultura virtual, docentes e discentes precisam construir/consolidar novas formas de conviver e aprender em rede, de alargar os currículos pelo enfraquecimento das fronteiras entre o "dentro da escola" e o "fora da escola". Em relação à mudança de papéis, os pesquisadores Silva e Silva Neto (2008) destacam que o docente e o discente têm assumido papéis diferentes em função da predominância da cultura virtual. Entendemos que isso faz sentido, pois na cultura virtual a uma facilitação a horizontalidade das relações entre os envolvidos, que pode contribuir para a criação de um clima de confiança e diálogo entre alunos e professor.

O desafio da formação de professores relaciona-se à preparação do docente para incorporar as TDIC nas práticas pedagógicas. As instituições de ensino precisam mudar os modelos tradicionais de formação, de capacitação, orientar o professor a utilizar as tecnologias de modo a contribuir na reconstrução de suas próprias formas de ensinar e compreender as potencialidades das TDIC na criação de novas possibilidades de ação educativa. Kenski (2012, p.105-106) afirma que o problema não está na dificuldade de domínio das competências para uso das TDIC pelos docentes. "O grande desafio está em encontrar formas produtivas e viáveis de integrar as TDIC no processo educativo, no quadro dos currículos atuais, da situação profissional dos docentes e das condições concretas de atuação em cada escola".

Em pesquisa realizada, Feldkercher (2012) constatou que os próprios professores reconhecem que falta formação a muitos deles para o uso apropriado das TDIC na educação. De forma espontânea, quatro participantes da pesquisa mencionaram que, sem a formação 
para o uso das tecnologias, muitos professores não conseguem criar metodologias para o uso das TDIC. Isso sinaliza ser necessário que os professores conheçam as tecnologias, suas possibilidades e limites, para poder utilizá-las no processo ensino- aprendizagem de maneira consciente e apropriada.

Ainda, sobre o uso das TDIC, Moran (2013) reconhece haver três etapas para a apropriação das tecnologias: na primeira etapa, as tecnologias são adotadas para melhorar o que sempre se fez; na segunda, as tecnologias são utilizadas para provocar mudanças parciais; e, na terceira, as tecnologias são usadas para promover transformações inovadoras no fazer. Portanto, a apropriação é um processo gradual e dinâmico sujeito a condições de quem a conduz.

Ao questionarem os docentes sobre os desafios que a profissão docente enfrenta no cenário da cultura virtual, Súnega e Guimarães (2017, p. 181-182) ressaltaram três questões que apareceram com destaque em suas narrativas:

[..] a dificuldade que os professores enfrentam em utilizar as ferramentas tecnológicas, no sentido técnico e operacional; os problemas relativos ao excesso de informação e pouco aprofundamento analítico sobre as mesmas devido à velocidade em que são geradas e disseminadas na rede informacional; a necessidade cotidiana de capturar a atenção dos discentes, pois os mesmos estão cada vez mais dispersos frente à informatividade e o entretenimento da cultura digital, especialmente facilitado pelos aparelhos de tecnologias móveis.

As questões destacadas por Súnega e Guimarães (2017) ligam-se ao desafio de transformar o grande volume e fluxo de informações em conhecimento. Diante disso, cabe ressaltar também a necessidade de saber processar a informação, pois ela, por si só, não promove o conhecimento. É necessário que o sujeito tenha capacidade reflexiva e crítica para desenvolver, compreender e usar adequadamente a informação, para que ocorra seu crescimento intelectual.

Para Moran (2013), a incorporação das TDIC requer a exigência de maior planejamento pelo docente de atividades diferenciadas, focadas em experiências, em pesquisa, em colaboração, em desafios e múltiplas linguagens. Com o forte apoio de situações reais, de simulações. Segundo o autor, este desafio coloca o planejamento e a organização do trabalho docente como condições indispensáveis para o desenvolvimento do trabalho docente, de modo a favorecer o processo educativo, propiciando a reflexão sobre as ações e a tomada de decisões.

De acordo com Wilson et al (2013, p. 17), o desafio está no fortalecimento da Alfabetização Midiática Informacional (AMI) entre os discentes, que: 
[...] requer que os próprios professores sejam alfabetizados em mídia e informação. $\mathrm{O}$ trabalho inicial com professores é a estratégia central para se alcançar um efeito multiplicador: de professores alfabetizados em termos informacionais para seus alunos e, eventualmente, para a sociedade em geral. Os professores alfabetizados em conhecimentos e habilidades midiáticas e informacionais terão capacidades aprimoradas de empoderar os alunos em relação a aprender a aprender, a aprender de maneira autônoma e a buscar a educação continuada.

De acordo com os autores, para que os docentes tenham capacidade de uso crítico das TDIC para a produção de conhecimento e conteúdo, faz-se necessário o fortalecimento da AMI por parte dos discentes. Kesnki (2013) afirma que, para adaptar-se à comunicação midiática, é necessário que o docente conheça as TDIC, para que possa lidar com elas de forma crítica, dado que, no ambiente acadêmico, é cada vez mais comum e necessária uma cultura midiática educativa, na qual encontram-se inseridas as TDIC, tanto na parte teórica, quanto prática. Frente a esta situação, as instituições educacionais enfrentam o desafio de estimular e favorecer a incorporação das TDIC no desenvolvimento do trabalho docente não só em parte do conteúdo, mas principalmente nos instrumentos de apoio na construção do saber, de forma a contribuir para elaborar, desenvolver e avaliar práticas educativas, capazes de promover o desenvolvimento intelectual a formação do discente como cidadão consciente e participante.

Silva e Stochi (2017) destacam que as TDIC na educação são meio ou instrumento para beneficiar o processo ensino-aprendizagem. Elas não resolvem os dilemas da educação, mas sua utilização adequada pode provocar mudanças significativas no modo de ensinar e aprender. Nesse contexto, Imbérnom (2010) destaca que para o uso das TDIC constituir uma transformação educativa significante no contexto educacional, muitos fatores são necessários e outros terão que mudar. Muitos estão nas mãos dos próprios docentes, que precisarão rever seu papel e sua responsabilidade no ambiente acadêmico, mas outros tantos escapam de seu controle e se inscrevem na esfera da gestão escolar e da própria sociedade.

\subsection{TDIC - Potenciais educativos}

Assim como Silva e Stochi (2017), vários pesquisadores destacam os benefícios e os potenciais educativos das TDIC, para o desenvolvimento do trabalho docente. Mas, para tal, há necessidade de haver formação docente que facilite e fundamente o acesso e o desempenho de docentes para lidar com essas tecnologias e fortalecer os processos de sua apropriação nas práticas pedagógicas. Em direção complementar, Fedoce (2010) entende que a utilização dos potenciais das TDIC ocorre de forma cada vez mais expressiva no contexto educacional, caracterizando novos formatos de educação, e apresenta ser uma das alternativas viáveis para atender demandas básicas relativas à promoção do desenvolvimento social e econômico do país. 
Para Oliveira e Moura (2015, p.80), as tecnologias "proporcionam que os alunos construam seus saberes a partir da comunicabilidade e interações com um mundo de pluralidades, no qual não há limitações geográficas, culturais e a troca de conhecimentos e experiências é constante". Dessa maneira, entende-se que as TDIC atuam como molas propulsoras e recursos dinâmicos de educação, à proporção que, quando bem utilizadas pelos docentes e discentes, favorecem a intensificação e a melhoria das práticas pedagógicas desenvolvidas em sala de aula e fora dela.

$\mathrm{Na}$ linha dos que admitem a contribuição positiva das TDIC, mesmo com desafios a superar, Silva e Stochi (2017) afirmam que o uso das TDIC, em sala de aula, possibilita

[....] novas formas de visualização dos conteúdos de aprendizagem; a visualização de lugares distantes e distintos; permitir que o aluno seja condutor do seu próprio conhecimento através da pesquisa; permitir aos professores, um acesso mais rápido as suas próprias dúvidas e aos questionamentos dos alunos; estimular a participação ativa dos estudantes de forma colaborativa.

Já para Carvalho (2016, p.22), essas possibilidades ocorrem porque as TDIC estão cada vez mais evoluídas, possibilitando capturar, articular integrar "leitura, escrita, visão, audição e faz emergir o conhecimento por simulação, pois torna possível a troca e intercâmbio de conhecimento, não apenas o produto acabado, mas, agora durante o processo de sua produção". Ainda, segundo Carvalho (2016), as TDIC propiciam a produção coletiva que rompe barreiras geográficas, nacionalidade, formação acadêmica ou limitação de área científica, favorece a lógica voltada para a solução de problema. Carvalho (2011) também ressalta que as TDIC oferecem potencialidades indiscutíveis e essenciais para o sucesso educacional. A sua utilização veio abrir caminho ao novo paradigma educacional, centrado na descoberta de aprendizagens por parte do discente, deixando cair por terra o velho método de transmissão de conhecimentos centrado essencialmente no docente. É neste contexto que as TDIC assumem um papel importante, na medida em que permitem um enriquecimento contínuo de saberes pela renovação nas formas de aprender e de ensinar.

Del Vecchio (2007, p. 72) reconhece que as TDIC "trazem um potencial de interatividade para a educação que permite a exploração e a citação de estruturas educacionais inovadoras conectadas às necessidades e objetivos atuais de nossa sociedade". Assim, o uso das TDIC no processo educativo visa garantir a dinamicidade e interatividade do aluno com os novos ambientes de aprendizagem. As tecnologias permitem ao professor se aproximar dos alunos e auxiliá-los de forma mais direta em sua aprendizagem. Havendo interatividade, as 
ideias vão se tornando parecidas e complementares, possibilitando a construção de conhecimentos para compartilhamento.

A interatividade é um desafio que exige do docente o desenvolvimento de competências para atuar como mediador desse processo, um implementador de situações para que a interação seja decisiva e produtiva, de modo a contribuir para que os discentes possam usufruir dos reais potenciais educativos das TDIC.

Oliveira (2014, p. 6), em seus estudos, concluiu que as práticas pedagógicas podem incorporar as vantagens e possibilidades oferecidas pelo uso das TDIC para aperfeiçoar o processo educativo no espaço acadêmico, entendendo que elas:

- Oferecem facilidades para a realização de atividades colaborativas e amplia as formas de interação;

Permitem flexibilizar o tempo e o espaço para a aprendizagem;

Viabilizam acesso a diferentes materiais, informações e modos de comunicação;

- Modificam os papéis e a relação entre alunos-professores e alunos-alunos; Incentivam o desenvolvimento da autonomia nos processos pedagógicos.

Moran (2013, p.31) corrobora os pesquisadores, ao destacar que:

Os espaços se multiplicam, mesmo sem sair do lugar (múltiplas atividades diferenciadas na mesma sala). As salas de aula podem tornar-se espaços de pesquisa, de desenvolvimento de projetos, de intercomunicação on-line, de publicação, com a vantagem de combinar o melhor do presencial e do virtual no mesmo espaço e ao mesmo tempo. Pesquisar de todas as formas, utilizando todas as mídias, todas as fontes, todas as maneiras de interação. Pesquisar às vezes todos juntos, outras em pequenos grupos, outras individualmente. Pesquisar na escola; outras, em diversos espaços e tempos. Combinar pesquisa presencial e virtual. Relacionar os resultados, compará-los, contextualizá-los, aprofundá-los, sintetizá-los. O conteúdo pode ser disponibilizado digitalmente. Predominam as atividades em tempo real interessantes, desafios, jogos, comunicação com outros grupos.

Ainda, conforme Moran (2013), os docentes podem utilizar as TDIC no desenvolvimento do seu trabalho, como apoio para a pesquisa, realização de atividades didáticas, comunicação com os alunos e dos alunos entre si, integração entre grupos dentro e fora da classe, publicação de páginas web, blogs, vídeos, participação em redes sociais, dentre muitas outras possibilidades. Nessa mesma direção, Kenski (2013, p. 76) assinala que as TDIC orientam para o uso de uma proposta diferente de ensino, enquanto "[...] condicionam os princípios, a organização e as práticas educativas e impõem profundas mudanças na maneira de organizar os conteúdos a serem ensinados, as formas como serão trabalhadas e acessadas as fontes de informação. E os modos individuais e coletivos, como irão ocorrer as aprendizagens”. 
Podemos considerar que há uma semelhança de algumas posições e interpretações dos potenciais educativos apontados pelos pesquisadores que podem ser sintetizadas na necessidade de competências para utilizar as TDIC e atitudes para que o processo ensino-aprendizagem seja significativo.

\subsection{TDIC nos documentos oficiais}

Ao se analisarem os desafios e potenciais educativos das TDIC no desenvolvimento do trabalho docente, é de grande relevância ressaltar que a incorporação das tecnologias é apresentada e incorporada em documentos oficiais, a exemplo do exposto no Decreto $\mathrm{n}^{\circ}$ 6.300, de 12 de dezembro de 2007, do Programa Nacional de Tecnologia Educacional (PROINFO) que determina o uso pedagógico das TDIC nas redes públicas de educação básica. Os objetivos do ProInfo são:

I- promover o uso pedagógico das tecnologias de informação e comunicação nas escolas de educação básica das redes públicas de ensino urbanas e rurais; II- fomentar a melhoria do processo de ensino e aprendizagem com o uso das tecnologias de informação e comunicação;

III- promover a capacitação dos agentes educacionais envolvidos nas ações do Programa;

IV- contribuir com a inclusão digital por meio da ampliação do acesso a computadores, da conexão à rede mundial de computadores e de outras tecnologias digitais, beneficiando a comunidade escolar e a população próxima às escolas;

V-contribuir para a preparação dos jovens e adultos para o mercado de trabalho por meio do uso das tecnologias de informação e comunicação; e VI- fomentar a produção nacional de conteúdos digitais educacionais.

(BRASIL, 2017).

A Lei n ${ }^{\circ}$ 13.005, de 25 de junho de 2014, do Plano Nacional de Educação (PNE) 20142024. No PNE 2014-2024, indica que o tema das tecnologias é apresentado em diversas partes do documento, prevendo a incorporação das modernas TDIC em articulação com a base nacional comum dos conteúdos curriculares. Analisando as 20 metas do PNE, encontramos estratégias direcionadas para a incorporação das tecnologias: meta 7, estratégias 7.15 e 7.20; meta 15 , estratégias 15.6:

Meta 7: 7.15- universalizar, até o quinto ano de vigência deste PNE, o acesso à rede mundial de computadores em banda larga de alta velocidade e triplicar, até o final da década, a relação computador/aluno(a) nas escolas da rede pública de educação básica, promovendo a utilização pedagógica das tecnologias da informação e da comunicação; 7.20- prover equipamentos e recursos tecnológicos digitais para a utilização pedagógica no ambiente escolar a todas as escolas públicas da educação básica, criando, inclusive, mecanismos para implementação das condições necessárias para a 
universalização das bibliotecas nas instituições educacionais, com acesso a redes digitais de computadores, inclusive a internet; (BRASIL, 2014, p. 64)

Meta 15: 15.6 - promover a reforma curricular dos cursos de licenciatura e estimular a renovação pedagógica, de forma a assegurar o foco no aprendizado do(a) aluno(a), dividindo a carga horária em formação geral, formação na área do saber e didática específica e incorporando as modernas tecnologias de informação e comunicação, em articulação com a base nacional comum dos currículos da educação básica, de que tratam as estratégias 2.1, 2.2, 3.2 e 3.3 deste PNE. (BRASIL, 2014, p. 79).

A Resolução $n^{\circ} 2$, de $1^{\circ}$ de julho de 2015, que define as Diretrizes Curriculares Nacionais (DCN) para a formação inicial em nível superior (cursos de licenciatura, cursos de formação pedagógica para graduados e cursos de segunda licenciatura) e para a formação continuada, também faz referência ao uso das TDIC e destaca:

- a necessidade de competência para usar as TDIC, no capítulo 2. Art. 5, item VI - "ao uso competente das Tecnologias de Informação e Comunicação (TIC) para o aprimoramento da prática pedagógica e a ampliação da formação cultural dos (das) professores (as) e estudantes" (BRASIL, 2015);

- a necessidade do domínio das TDIC para o desenvolvimento da aprendizagem, no capítulo 3, no art. 8, item V - "relacionar a linguagem dos meios de comunicação à educação, nos processos didático-pedagógicos, demonstrando domínio das tecnologias de informação e comunicação para o desenvolvimento da aprendizagem" (BRASIL, 2015);

- a necessidade de disponibilidade com qualidade e quantidade das TDIC nas instituições de formação, no capítulo 4, art. 11, item VII - "recursos pedagógicos como biblioteca, laboratórios, videoteca, entre outros, além de recursos de tecnologias da informação e da comunicação, com qualidade e quantidade, nas instituições de formação". (BRASIL, 2015).

Nos referidos documentos oficiais, embora apresentem-se referências em relação à incorporação e ao uso das TDIC no contexto educacional, percebe-se a ausência de uma análise sobre a forma como as TDIC determinam os rumos dos atuais processos de ensino e de aprendizagem. Assim, torna-se imperativo refletir sobre o modo pelo qual a educação incorpora as tecnologias, especialmente no que se refere à formação de professores e à introdução das tecnologias midiáticas no ambiente acadêmico. A transposição das TDIC para as práticas educacionais deve ser feita por meio de uma análise minuciosa das suas vantagens e limites, permitindo assim a crítica de uma possível incorporação instrumental e reificada dessas tecnologias. 


\section{CONSIDERAÇÕES FINAIS}

Segundo as concepções dos pesquisadores, os docentes têm desafios a enfrentar e conhecimentos novos para adquirir. Por isso, se faz necessário conhecimento amplo das diversas tecnologias presentes no mundo virtual. Na busca de um ensino de qualidade, as TDIC auxiliam o processo de mediação do conhecimento em sala de aula, favorecendo a interdisciplinaridade, a ampliação de informação diante da pesquisa e, consequentemente, possibilitam movimentos autônomos do processo de aprendizagem. Porém, não basta as tecnologias estarem à disposição para os docentes, posto que eles precisam buscar formação para usá-las, de modo a usufruir os seus potenciais educativos.

Para que os desafios sejam vencidos e os potenciais educativos das TDIC sejam vivenciados no contexto educacional, há necessidade de uma mudança no fazer pedagógico, que implica ações comunicativas pelas e para as quais os docentes necessitam se preparar continuamente. Essas ações têm de ser contextualizadas nas experiências e no cotidiano docente para que possam proporcionar conteúdos teórico-práticos.

Os processos interativos de comunicação, colaboração e criatividade são indispensáveis ao profissional que vai atuar no contexto da cultura virtual.

\section{REFERÊNCIAS}

ALONSO, Katia Morosov et al. Aprender e ensinar em tempos de Cultura Digital, Em Rede Revista de Educação a Distância, Porto Alegre-RS, v.1, n.1, 2014. Disponível em: https://www.aunirede.org.br/revista/index.php/emrede/article/view/16. Acesso em: $30 \mathrm{jul}$. 2019

BRASIL. Decreto $n^{o}$ 6.300, de 12 de dezembro de 2007. Dispõe sobre o Programa Nacional de Tecnologia Educacional -ProInfo. 2007. Disponível em: http://www.planalto.gov.br/ccivil_03/_Ato2007-2010/2007/Decreto/D6300.htm. Acesso em: 30 jul. 2019.

BRASIL. Lei n. 13.005, de 25 de junho de 2014. Aprova o Plano Nacional de Educação PNE e dá outras providências. Diário Oficial da União, Brasília, DF, 26 jun. 2014. Disponível em: http://www.planalto.gov.br/ccivil_03/_ato2011-2014/2014/lei/113005.htm. Acesso em: 30 jul. 2019.

. Resolução $N^{o} 2$, de $1^{o}$ de julho de 2015. Diretrizes Curriculares Nacionais para a formação inicial em nível superior. Define as Diretrizes Curriculares Nacionais para a formação inicial em nível superior (cursos de licenciatura, cursos de formação pedagógica para graduados e cursos de segunda licenciatura) e para a formação continuada. Disponível em: http://portal.mec.gov.br/docman/agosto-2017-pdf/70431-res-cne-cp-002-03072015pdf/file. Acesso em: 30 jul. 2019. 
CARVALHO, Lucinda de Assunção Carvalho. Aprender com as TIC. 2011. Disponível em: https://core.ac.uk/download/pdf/153411336.pdf. Acesso em: 30 jul. 2019.

CARVALHO, Rosiani. As tecnologias no cotidiano escolar: possibilidades de articular o trabalho pedagógico aos recursos tecnológicos. 2016. Disponível em:

http://www.diaadiaeducacao.pr.gov.br/portals/pde/arquivos/1442-8.pdf. Acesso em: $30 \mathrm{jul}$. 2019.

CASTELLS, Manuel. Sociedade em rede. São Paulo: Paz e Terra, 2009. (A era da informação: economia, sociedade e cultura, v.1)

CERVO, Amado Luiz.; BERVIAN, Pedro Alcino.; SILVA, Roberto. da. Metodologia Científica. 6. ed. São Paulo: Pearson Education do Brasil Ltda, 2007.

DEL VECCHIO, Rosangela. A experiência na formação do professor que atua em ambiente virtuais. 2007. 192 f. Dissertação (Mestrado em Educação) Pontifícia Universidade Católica de São Paulo,2007. Disponível em:

https://tede2.pucsp.br/bitstream/handle/9986/1/Rosangela\%20Del\%20Vecchio.pdf. Acesso em: 30 jul. 2019.

FEDOCE, Rosangela Spagnol. A tecnologia móvel e os potenciais da comunicação na Educação. 2010. 274 f. Dissertação (Mestrado em Comunicação Social) - Universidade Metodista de São Paulo, 2010. Disponível em:

http://tede.metodista.br/jspui/bitstream/tede/927/1/Rosangela\%20Fedoce.pdf. Acesso em: 30 jul. 2019.

FELDKERCHER, Nadiane. Tecnologias aplicadas à educação superior presencial e à distância: a prática dos professores. In: ENCONTRO NACIONAL DE DIDÁTICA E PRÁTICAS DE ENSINO - UNICAMP. 16, 2012, Campinas - SP. Anais [...]. Campinas, SP: Faculdade de Educação da UNICAMP, 2012

IMBERNÓN, Francisco. Formação docente e profissional: formar-se para a mudança e a incerteza. 7. ed. São Paulo: Cortez, 2010.

KENSKI, Vani. Moreira. Educação e tecnologias: o novo ritmo da informação. Papirus editora, 2012.

. Tecnologias e ensino presencial e a distância. 9. ed. Campinas, SP: Papirus, 2013

LÉVY, Pierre. O que é o virtual? São Paulo: Editora 34, 1996.

MORAN, José. Desafios que as tecnologias digitais nos trazem. 2013. Disponível em: http://www.eca.usp.br/prof/moran/site/textos/tecnologias_eduacacao/desaf_int.pdf. Acesso em: 30 jul. 2019.

OLIVEIRA, Cláudio de; MOURA, Samuel Pedrosa. Tic's na educação: a utilização das tecnologias da informação e comunicação na aprendizagem do aluno. Pedagogia em Ação, n.1, v.15, 2015. Disponível em:

http://periodicos.pucminas.br/index.php/pedagogiacao/article/view/11019. Acesso em: $30 \mathrm{jul}$. 2019. 
OLIVEIRA, Maria das Graças Souza. As Novas Tecnologias na Educação: otimizando o processo de ensino-aprendizagem na sala de aula. Só Pedagogia, abril 2014. Disponível em: https://www.pedagogia.com.br/artigos/as_novas tecnologias/. Acesso em: 30 jul. 2019.

SILVA, Ketiuce Ferreira; SILVA NETO, Sertório Amorim e. O processo de ensinoaprendizagem apoiado pelas tics: repensando práticas educacionais. 2008. Disponível em: http://ketiuce.com.br/TDAE/Artigo_TDAE_Ketiuce2.pdf. Acesso em: 30 jul. 2019.

SILVA, Lucimar da; STOCHI, Claudia Roberta Rosa S. As novas tecnologias no contexto educacional e a formação continuada: a busca permanente. 2017. Disponível em: https://blog.abmes.org.br/as-novas-tecnologias-no-contexto-educacional-e-a-formacaocontinuada-a-busca-permanente/. Acesso em: 25 jul. 2019

SÚNEGA, Paula Beatriz Camargo; GUIMARÃES, Iara Vieira Guimarães. A docência e os desafios da cultura digital. Revista Reflexão e Ação, v. 25, n. 1, p. 178-197, jan./abr. 2017. Disponível em: https://online.unisc.br/seer/index.php/reflex/article/view/7856. Acesso em 25 jul. 2019

WILSON, Carolyn; AKYEMPONG, Kwame; CHEUNG, Chi-Kim; GRIZZLE, Alton; TUAZON, Ramon. Alfabetização midiática e informacional: currículo para formação de professores. Brasília-DF: UNESCO-UFTM, 2013.

\section{SOBRE AS AUTORAS}

Rosemar Rosa é mestre em Educação pela Universidade de Uberaba. Doutoranda no mesmo programa. Tem graduação em Biblioteconomia pelo Centro Universitário de Formiga. Atualmente é professora pesquisadora do Instituto Federal e Educação, Ciência e Tecnologia do Triângulo Mineiro - IFTM. É bibliotecária do Campus Avançado Uberaba Parque Tecnológico - IFTM.

E-mail: rose@iftm.edu.b

ORCID: https://orcid.org/0000-0002-2048-9195

Sálua Cecílio possui licenciatura em Pedagogia pela Faculdade de Filosofia, Ciências e Letras Santo Tomás de Aquino, Uberaba-MG, mestrado em Psicologia Social pela Pontifícia Universidade Católica de São Paulo e doutorado em Sociologia pela Universidade de São Paulo. Atualmente é pesquisadora e professora da Universidade de Uberaba. Atua no Programa de Pós-Graduação em Educação, como docente dos cursos de Mestrado e Doutorado. Desde 2017, coordena o referido Programa.

E-mail: salua.cecilio@uniube.br

ORCID: https://orcid.org/0000-0001-6035-1636 